\title{
(2) OPEN ACCESS \\ Insulin doses requirements in patients with type 1 diabetes using glargine U300 or degludec in routine clinical practice
}

\author{
Florentino Carral San Laureano (1) , Mariana Tomé Fernández-Ladreda, \\ Ana Isabel Jiménez Millán, Concepción García Calzado, \\ María del Carmen Ayala Ortega
}

Endocrinology and Nutrition, University Hospital of Puerto Real, Puerto Real, Andalucía, Spain

Correspondence to Dr Florentino Carral San Laureano, Endocrinology and Nutrition, University Hospital of Puerto Real, Puerto Real 11510, Spain;

florencarral@hotmail.com

Accepted 5 March 2021 Published Online First 26 March 2021

\section{Check for updates}

(C) American Federation for Medical Research 2021. Re-use permitted under CC BY-NC. No commercial re-use. Published by BMJ.

\footnotetext{
To cite: Carral San Laureano F, Tomé Fernández-Ladreda $\mathrm{M}$, Jiménez Millán Al, et al. J Investig Med 2021;69:983-988.
}

\section{ABSTRACT}

There are not many real-world studies evaluating daily insulin doses requirements (DIDR) in patients with type 1 diabetes (T1D) using second-generation basal insulin analogs, and such comparison is necessary. The aim of this study was to compare DIDR in individuals with T1D using glargine $300 \mathrm{UI} /$ $\mathrm{mL}$ (IGlar-300) or degludec (IDeg) in real clinical practice. An observational, retrospective study was designed in 412 patients with T1D (males: 52\%; median age $37.0 \pm 13.4$ years, diabetes duration: $18.7 \pm 12.3$ years) using IDeg and IGla-300 $\geq 6$ months to compare DIDR between groups. Patients using IGla-300 ( $n=187)$ were more frequently males ( $59 \%$ vs $45.8 \% ; p=0.004$ ) and had lower glycosylated hemoglobin (HbA1c) (7.6 \pm 1.2 vs $8.1 \% \pm 1.5 \% ; p<0.001)$ than patients using IDeg $(\mathrm{n}=225)$. Total $(0.77 \pm 0.36 \mathrm{unit} / \mathrm{kg} /$ day), basal $(0.43 \pm 0.20 \mathrm{unit} / \mathrm{kg} /$ day $)$ and prandial $(0.33 \pm 0.23$ unit/kg/day) DIDR were similar in IGla-300 and IDeg groups. Patients with $\mathrm{HbA} 1 \mathrm{c} \leq 7 \%(n=113)$ used significantly lower basal $(p=0.045)$ and total $(p=0.024)$ DIDR, but not prandial insulin $(p=0.241)$, than patients with $\mathrm{HbA} 1 \mathrm{c}$ between $7.1 \%$ and $8 \%$ and $>8 \%$. Patients using IGla-300 and IDeg used similar basal, prandial and total DIDR regardless of metabolic control subgroup. No difference in basal, prandial and total DIDR was observed between patients with T1D using IGla-300 or IDeg during at least 6 months in routine clinical practice.

\section{INTRODUCTION}

Type 1 diabetes (T1D) is a chronic disease with personal, socioeconomic and health burdens. In long term, poor metabolic control in patients with T1D promotes development and progression of late microvascular and macrovascular complications, mean cause of morbidity, mortality and decreased quality of life. ${ }^{1}$ Results of the Diabetes Control and Complications Trial $(\mathrm{DCCT})^{2}$ and the Epidemiology of Diabetes Interventions and Complications Study (EDIC) ${ }^{3}$ demonstrated that intensive insulin therapy in patients with T1D, to achieve glycosylated hemoglobin (HbA1c) levels as close to normal

\section{Significance of this study}

What is already known about this subject?

- Despite the fact that glargine U300 (IGla300) and degludec (IDeg) basal analogs were introduced in 2015 , to date, few comparative studies have been published and information about comparative daily insulin dose requirements (DIDR) comes only from studies in patients with type 2 diabetes, which reported that patients treated with IGla-300 had higher daily insulin doses requirements compared with IDeg.

- To date, only limited studies comparing IGla-300 with IDeg insulins in people with type 1 diabetes (T1D) are available.

- There are not many real-world studies evaluating daily insulin doses requirements in patients with T1D using secondgeneration basal insulin analogs, and such comparison is necessary.

as possible, delayed the development and progression of microvascular and macrovascular complications compared with conventional insulin therapy. Recently, the DCCT/ EDIC study group reported that 30 years of excellent versus poor glycemic control substantially reduced all-cause mortality and resulted in a gain of $\sim 1.62$ quality-adjusted life-years and averted $\sim$ US\$90900 in costs of complications per participant. ${ }^{4}$

Since the publication of DCCT, there have been numerous and important innovations in the treatment of diabetes, such as the release of new basal and prandial insulin analogs that have a more 'physiological' effect and are safer, ${ }^{56}$ implementations of structured advances education programs ${ }^{7}$ and development and increase in use both of continuous subcutaneous insulin infusion devices and continuous and flash glucose monitoring systems. ${ }^{89}$ However, despite these advances, some studies in EE.UU and Europe in patients with T1D have reported 


\section{Significance of this study}

What are the new findings?

- A total of 412 patients with T1D who were receiving IGla-300 or IDeg during at least 6 months immediately preceding the inclusion date were included in the study.

- Total $(0.77 \pm 0.36 \mathrm{unit} / \mathrm{kg} /$ day $)$, basal $(0.43 \pm 0.20 \mathrm{unit} / \mathrm{kg} /$ day) and prandial $(0.33 \pm 0.23$ unit $/ \mathrm{kg} /$ day) daily insulin doses requirements were similar between IGla300 and IDeg groups.

- Patients with glycosylated hemoglobin (HbA1c) levels $\leq 7 \%$ ( $n=113$ ) used significantly lower basal and total daily insulin doses, but not prandial insulin than both patients with $\mathrm{HbA1c}$ levels between $7.1 \%$ and $8 \%$ $(n=151)$ and $>8 \%(n=148)$.

- Those patients with worst metabolic control (HbA1C $\geq 8 \%$ ) used higher basal, prandial and total daily insulin doses than patients in the other two subgroups of metabolic control.

- Patients using IGla-300 and IDeg had similar basal, prandial and total daily insulin doses requirements in all metabolic control subgroups.

\section{How might these results change the focus of research}

\section{or clinical practice?}

- Our study provides relevant information about our patients with T1D with stable basal-bolus insulin injections, using IGla-300 or IDeg as the basal insulin, in whom we did not observe any difference in basal, prandial or total daily insulin doses requirements.

a worsening in time in metabolic control, mainly in adolescent patients. ${ }^{10} 11$

The second-generation long-acting insulin analogs, glargine U300 UI/mL (IGla-300) and degludec (IDeg), were introduced in 2015 and have shown, in randomized controlled trials (RCTs), an increased stability, which translates to an increased flexibility in timing of administration $^{12} 13$ and reduced risk of hypoglycemia compared with glargine U100 UI/mL insulin (IGla-100), ${ }^{14}{ }^{15}$ results that have been reproduced in several real-world studies (RWS), ${ }^{16-21}$ although others have reported no differences in hypoglycemia between first-generation and secondgeneration basal analogs. ${ }^{22-25}$ Otherwise, a number of RCTs and RWS have reported higher daily insulin doses requirements (DIDR) with IGla-300 121520 and lower with IDeg, ${ }^{13} 141821$ compared with IGla-100, although some studies failed to detect these difference. ${ }^{17} 23-31$

To date, only limited studies comparing IGla-300 and IDeg in people with T1D are available. ${ }^{32-34}$ In this sense, there are not many RWS evaluating DIDR in patients with T1D using second-generation basal insulin analogs, and such comparison is necessary. This study aimed to compare the DIDR in individuals with T1D using IDeg and IGla-300 in real clinical practice.

\section{MATERIALS AND METHODS}

\section{Data source and subjects}

The study was designed as a retrospective, single-center, observational study including patients with T1D who attended their routine checkups in Endocrinology Unit during the period from 1 June 2019 to 31 December 2019. Anonymized participant data were collected from cumulative database of patients with T1D, used for clinical research and quality control, which incorporate predefined variables coming both from electronic clinic history and other health variables daily included by endocrinologists and diabetes specialized nurses.

Selected patients must satisfy all inclusion criteria and not meet any exclusion criteria. Inclusion criteria include (1) individuals with T1D aged 17-69 years and at least 1 year of diabetes duration; (2) treatment for at least 6 months with stable basal-bolus insulin injections, with IGla300 or IDeg as the basal insulin and rapid-acting insulin analogs before at least one meal. Exclusion criteria were: (1) pregnancy women; (2) those patients using an insulin pump or another long-acting (NPH, Determir, IGla-100) or premixed insulin during 2019. All patients wih T1D attended to in our specialized unit were incorporated in an individualized education program, including management of diet and physical activity, and many patients were instructed on carbohydrate counting education. Generally, all patients were instructed to optimize both basal insulin doses, to maintain morning fasting glucose between 80 and $130 \mathrm{mg} / \mathrm{dL}$, and rapid-acting insulin to keep 2-hour postprandial glucose $<180 \mathrm{mg} / \mathrm{dL}$.

\section{Variables}

The following data included in the database were evaluated: (1) health variables: gender, age, diabetes duration, active smoking, body weight, height and body mass index (BMI, $\left.\mathrm{kg} / \mathrm{m}^{2}\right)$; (2) analytical variables: HbA1c levels obtained within the previous 3 months and measured in our hospital laboratory. HbA1c was standardized to the DCCT reference range (20-42 mmol/mol; 4.05\%-6.05\%). Patients were subclassified in three metabolic control subgroups: HbA1c $\leq 7 \%$, HbA1c 7.1\%-8\% and HbA1c $\geq 8 \%$. Albuminuria obtained within the previous 3 months. The clinical definition of microalbuminuria used was two positive tests from three samples taken within 1 year, with an albumin/ creatinine ratio of $30-300 \mathrm{mg} / \mathrm{g}$ (approximately $3-30 \mathrm{mg} /$ mmol). Macroalbuminuria was defined as an albumin/ creatinine ratio $>300 \mathrm{mg} / \mathrm{g}$ (approximately $30 \mathrm{mg} / \mathrm{mmol}$ ); (3) treatment variables: type of basal insulin (IGla-300 or IDeg), units of basal, prandial and total daily, use of noninsulin hypoglycemic agents, patients using prandial insulin adjustment by carbohydrate counting, patients using FreeStyle Flash glucose monitoring system, antihypertensive treatment, lipid-lowering treatment; (4) diabetic complications: macrovascular disease (known ischemic heart disease, stroke, peripheral vascular disease or amputation), diabetic retinopathy (presence of any type of diabetic retinopathy or treatment with laser and/or surgery), diabetic nephropathy (defined as albuminuria, dialysis or kidney transplant).

\section{Statistical analysis}

All statistical analyses were performed with SPSS V.12.0 for Windows (IBM, Armonk, New York, USA). Variables were preliminarily tested for normal distribution with the Kolmogorov-Smirnov test. Descriptive statistics are presented in terms of means with SD or counts 
Table 1 Clinical characteristics and chronic complications in T1D $(n=412)$

\begin{tabular}{|c|c|c|c|c|}
\hline & $\begin{array}{l}\text { All patients } \\
(n=412)\end{array}$ & $\begin{array}{l}\text { Glargine U300 } \\
(n=187)\end{array}$ & $\begin{array}{l}\text { Degludec } \\
(n=225)\end{array}$ & $P$ value \\
\hline Age (years) & $37.0 \pm 13.4$ & $37.7 \pm 14.1$ & $36.6 \pm 12.8$ & 0.376 \\
\hline Gender male & $214(52 \%)$ & $111(59.4 \%)$ & $103(45.8 \%)$ & 0.004 \\
\hline Diabetes duration (years) & $18.7 \pm 12.3$ & $17.6 \pm 12.6$ & $19.8 \pm 11.9$ & 0.112 \\
\hline Weight (kg) & $72.0 \pm 14.9$ & $71.7 \pm 13.7$ & $72.3 \pm 15.9$ & 0.759 \\
\hline BMI $\left(\mathrm{kg} / \mathrm{m}^{2}\right)$ & $25.3 \pm 4.6$ & $25.1 \pm 4.5$ & $25.4 \pm 4.8$ & 0.551 \\
\hline $\mathrm{HbA1c}(\%)$ & $7.8 \pm 1.4$ & $7.6 \pm 1.2$ & $8.1 \pm 1.5$ & $<0.001$ \\
\hline Patients with $\mathrm{HbA} 1 \mathrm{c} \leq 7 \%$ & $113(27.4 \%)$ & $65(35.3 \%)$ & $48(21.5 \%)$ & 0.001 \\
\hline Patients with $\mathrm{HbA} 1 \mathrm{c} \geq 8 \%$ & $148(35.9 \%)$ & $53(28.3 \%)$ & $95(42.2 \%)$ & 0.003 \\
\hline Carbohydrate counting (\%) & $106(25.7 \%)$ & $47(25.1 \%)$ & $59(26.2 \%)$ & 0.458 \\
\hline Patients with FSL (\%) & $80(19.0 \%)$ & $27(14.4 \%)$ & $44(19.6 \%)$ & 0.107 \\
\hline Time in range $70-180 \mathrm{mg} / \mathrm{dL}(\%)$ & $47.3 \pm 18.0$ & $51.1 \pm 14.6$ & $45.0 \pm 19.5$ & 0.183 \\
\hline Time in hypoglycemia <70 mg/dL (\%) & $6.8 \pm 6.6$ & $9.2 \pm 8.3$ & $5.8 \pm 4.4$ & 0.053 \\
\hline Time in hyperglycemia >180 mg/dL (\%) & $46.5 \pm 19.9$ & $39.6 \pm 16.4$ & $50.5 \pm 20.7$ & 0.023 \\
\hline Active smoking (\%) & $101(24.5 \%)$ & $44(23.5 \%)$ & $57(25.3 \%)$ & 0.379 \\
\hline Antihypertensive treatment (\%) & $78(18.9 \%)$ & $33(17.6 \%)$ & $45(20.0 \%)$ & 0.307 \\
\hline Lipid-lowering treatment (\%) & $147(35.7 \%)$ & $65(34.7 \%)$ & $82(36.4 \%)$ & 0.349 \\
\hline Diabetic retinopathy (\%) & $194(47.0 \%)$ & $79(42.2 \%)$ & $115(51.1 \%)$ & 0.056 \\
\hline DR mild-to-moderate & $114(27.6 \%)$ & $43(23.0 \%)$ & $71(31.5 \%)$ & \\
\hline Laser therapy & $53(12.9 \%)$ & $29(15.5 \%)$ & $24(10.6 \%)$ & \\
\hline Surgery & $27(6.6 \%)$ & $7(3.6 \%)$ & $20(8.9 \%)$ & \\
\hline Diabetic nephropathy & $52(12.6 \%)$ & $20(10.7 \%)$ & $32(14.2 \%)$ & 0.327 \\
\hline Albuminuria & $42(10.2 \%)$ & $16(8.6 \%)$ & $26(11.6 \%)$ & \\
\hline Dialysis of kidney transplant & $10(2.4 \%)$ & $4(2.1 \%)$ & $6(2.7 \%)$ & \\
\hline Macrovascular complications (\%) & $23(5.6 \%)$ & $9(4.8 \%)$ & $14(6.2 \%)$ & 0.089 \\
\hline
\end{tabular}

BMI, body mass index; DR, diabetic retinopathy; FSL, freestyle libre; HbA1C, glycosylated hemoglobin; T1D, type 1 diabetes.

and percentages depending on the nature of the variable described. Intergroup differences of normally or nonnormally distributed data were tested for significance with the unpaired Student's t-test or Mann-Whitney U test, respectively. Differences in categorical variables were analyzed by $\chi^{2}$ test or Fisher's exact test, as appropriate. Setting daily basal insulin dose and daily total insulin dose as the dependent variables, two separate linear regression analysis were performed. Independent variables included in linear regression analysis were age, gender, diabetes duration, HbA1c, type of basal insulin, prandial insulin dose and microvascular complication. A p value of $<0.05$ was considered to indicate statistical significance.

\section{RESULTS}

A total of 412 patients with T1D (males: 52\%; median age: $37.0 \pm 13.4$ years, median diabetes duration: $18.7 \pm 12.3$ years; median HbA1c: $7.8 \% \pm 1.4 \%$ ) who were receiving IGla-300 or IDeg during at least 6 months immediately preceding the inclusion date were included in the study. The patients in IGla-300 group were more frequently males (59\% vs 45.8\%; p=0.004), had lower HbA1c levels $(7.6 \pm 1.2 \%$ vs $8.1 \% \pm 1.5 \% ; \mathrm{p}<0.001)$, higher proportion of patients with $\mathrm{HbA} 1 \mathrm{c} \leq 7 \%$ (35.3\% vs $21.5 \%$; $\mathrm{p}=0.001)$ and lower proportion of patients with $\mathrm{HbA} 1 \mathrm{c} \geq 8 \%(28.3 \%$ vs $42.2 \% ; p=0.003$ ) than patients using IDeg (table 1 ). There were no statistical difference ( $42 \%$ vs $53 \%$ vs $53 \%$, $\mathrm{p}=0.122$, in HbA1c $\leq 7 \%, 7.1 \%-8 \%$ and $>8 \%$ subgroups, respectively) between metabolic control subgroups.
Non-insulin hypoglycemic agents and DIDR in IGla300 and IDeg groups are presented in table 2. Non-insulin hypoglycemic agents were prescribed in 30 patients $(7.2 \%)$ and more frequently were metformin (26 patients; $6.3 \%$ of total) and sodium-glucose co-transporter- 2 inhibitors (12 patients; $2.9 \%$ of total). Total $(0.77 \pm 0.36$ unit $/ \mathrm{kg} /$ day $)$, basal $(0.43 \pm 0.20 \mathrm{unit} / \mathrm{kg} / \mathrm{day} ; 58 \%$ of total insulin) and prandial

Table 2 Non-insulin hypoglycemic agents and daily insulin doses requirements in T1D using glargine U300 or degludec $(n=412)$

\begin{tabular}{|c|c|c|c|c|}
\hline & $\begin{array}{l}\text { All patients } \\
(n=412)\end{array}$ & $\begin{array}{l}\text { Glargine U300 } \\
(n=187)\end{array}$ & $\begin{array}{l}\text { Degludec } \\
(n=225)\end{array}$ & $P$ value \\
\hline $\begin{array}{l}\text { Non-insulin } \\
\text { antidiabetics (\%) }\end{array}$ & $30(7.3)$ & $11(5.9)$ & $19(8.4)$ & 0.233 \\
\hline \multicolumn{5}{|l|}{ Basal insulin } \\
\hline Unit/day & $31.5 \pm 16.9$ & $30.1 \pm 14.9$ & $32.2 \pm 18.4$ & 0.759 \\
\hline Unit/kg/day & $0.43 \pm 0.20$ & $0.43 \pm 0.19$ & $0.44 \pm 0.21$ & 0.563 \\
\hline \multicolumn{5}{|l|}{ Prandial insulin } \\
\hline Unit/day & $23.5 \pm 16.9$ & $22.5 \pm 16.1$ & $23.2 \pm 16.0$ & 0.603 \\
\hline Unit/kg/day & $0.33 \pm 0.23$ & $0.32 \pm 0.23$ & $0.33 \pm 0.20$ & 0.851 \\
\hline \multicolumn{5}{|l|}{ Total insulin } \\
\hline Unit/day & $54.0 \pm 29.1$ & $52.8 \pm 27.4$ & $55.4 \pm 29.5$ & 0.383 \\
\hline Unit/kg/day & $0.77 \pm 0.36$ & $0.76 \pm 0.35$ & $0.76 \pm 0.33$ & 0.683 \\
\hline $\begin{array}{l}\text { Basal/Total insulin } \\
\text { ratio }\end{array}$ & $0.58 \pm 0.14$ & $0.59 \pm 0.14$ & $0.58 \pm 0.14$ & 0.441 \\
\hline
\end{tabular}

T1D, type 1 diabetes. 
Table 3 Daily insulin doses requirements by metabolic control subgroups in T1D using glargine U300 or degludec

\begin{tabular}{|c|c|c|c|c|c|c|}
\hline & \multicolumn{2}{|c|}{$\begin{array}{l}\text { HbA1c } \leq 7 \% \\
\text { (IGla: } 65 \text { P; IDeg: } 48 \text { P) }\end{array}$} & \multicolumn{2}{|c|}{$\begin{array}{l}\text { HbA1c 7.1\%-8\% } \\
\text { (IGla: } 69 \text { P; IDeg: } 82 \text { P) }\end{array}$} & \multicolumn{2}{|c|}{$\begin{array}{l}\text { HbA1c } \geq 8 \% \\
\text { (IGla: } 53 \text { P; IDeg: } 95 \text { P) }\end{array}$} \\
\hline & & $P$ value & & $P$ value & & $P$ value \\
\hline \multicolumn{7}{|c|}{ Basal insulin } \\
\hline \multicolumn{7}{|l|}{ Unit/day } \\
\hline IGla-300 & $25.8 \pm 13.4$ & 0.781 & $30.8 \pm 15.7$ & 0.780 & $35.1 \pm 13.8$ & 0.779 \\
\hline IDeg & $26.6 \pm 16.8$ & & $31.6 \pm 19.0$ & & $35.8 \pm 18.1$ & \\
\hline \multicolumn{7}{|l|}{ Unit/kg/day } \\
\hline IGla-300 & $0.36 \pm 0.16$ & 0.558 & $0.43 \pm 0.17$ & 0.870 & $0.51 \pm 0.18$ & 0.643 \\
\hline IDeg & $0.38 \pm 0.20$ & & $0.42 \pm 0.21$ & & $0.49 \pm 0.21$ & \\
\hline \multicolumn{7}{|c|}{ Prandial insulin } \\
\hline \multicolumn{7}{|l|}{ Unit/day } \\
\hline IGla-300 & $18.7 \pm 12.4$ & 0.552 & $25.1 \pm 19.9$ & 0.055 & $24.5 \pm 14.6$ & 0.185 \\
\hline IDeg & $20.0 \pm 9.8$ & & $19.7 \pm 11.1$ & & $28.4 \pm 20.2$ & \\
\hline \multicolumn{7}{|l|}{ Unit/kg/day } \\
\hline IGla-300 & $0.26 \pm 0.17$ & 0.404 & $0.35 \pm 0.27$ & 0.070 & $0.37 \pm 0.21$ & 0.451 \\
\hline IDeg & $0.29 \pm 0.11$ & & $0.27 \pm 0.16$ & & $0.40 \pm 0.26$ & \\
\hline \multicolumn{7}{|l|}{ Total insulin } \\
\hline \multicolumn{7}{|l|}{ Unit/day } \\
\hline IGla-300 & $44.7 \pm 22.2$ & 0.893 & $56.2 \pm 32.3$ & 0.285 & $59.6 \pm 24.7$ & 0.342 \\
\hline IDeg & $45.3 \pm 24.1$ & & $51.0 \pm 25.1$ & & $64.3 \pm 33.2$ & \\
\hline \multicolumn{7}{|l|}{ Unit/kg/day } \\
\hline IGla-300 & $0.64 \pm 0.29$ & 0.857 & $0.79 \pm 0.37$ & 0.135 & $0.88 \pm 0.34$ & 0.782 \\
\hline IDeg & $0.64 \pm 0.24$ & & $0.69 \pm 0.28$ & & $0.89 \pm 0.38$ & \\
\hline \multicolumn{7}{|l|}{$\mathrm{B} / \mathrm{T}$ ratio } \\
\hline IGla-300 & $0.60 \pm 0.15$ & 0.032 & $0.58 \pm 0.15$ & 0.217 & $0.60 \pm 0.13$ & 0.269 \\
\hline IDeg & $0.55 \pm 0.11$ & & $0.61 \pm 0.14$ & & $0.57 \pm 0.15$ & \\
\hline
\end{tabular}

B/T, basal/total insulin; HbA1C, glycosylated hemoglobin; IDeg, insulina degludec; IGla-300, insulina glargina 300 UI/mL; P, patients; T1D, type 1 diabetes.

$(0.33 \pm 0.23$ unit $/ \mathrm{kg} /$ day; $42 \%$ of total insulin) DIDR were similar between IGla-300 and IDeg groups. A sensitivity analysis for DIDR by metabolic control groups was made and results are shown in table 3. Patients with $\mathrm{HbA} 1 \mathrm{c}$ levels $\leq 7 \%(\mathrm{n}=113)$ used significantly lower basal $(\mathrm{p}=0.045)$ and total daily insulin doses $(p=0.024)$, but not prandial insulin $(p=0.241)$ than both patients with HbA1c levels between $7.1 \%$ and $8 \%(n=151)$ and $>8 \%(n=148)$. Those patients with worst metabolic control $(\mathrm{HbA} 1 \mathrm{c} \geq 8 \%)$ used higher basal, prandial and total daily insulin doses than patients in the other two subgroups of metabolic control. No difference was observed in the basal/total insulin ratio between metabolic control subgroups. Finally, patients using IGla-300 and IDeg had similar basal, prandial and total DIDR in all metabolic control subgroups. In the linear regression analysis, age $(\beta=-0.144, p=0.041$ and $\beta=-0.091, p=0.009)$, HbA1c $(\beta=0.240, p<0.001$ and $\beta=0.134, p<0.001)$, prandial doses $(\beta=0.301, p<0.001$ and $\beta=0.805, p<0.001)$ and microvascular complication $(\beta=0.184, p=0.007$ and $\beta=0.096, p=0.003$ ) were significantly associated with daily basal insulin doses and total daily insulin doses, respectively, without association with type of basal insulin $(\beta=-0.042$, $\mathrm{p}=0.421$ and $\beta=-0.024, \mathrm{p}=0.403$ ).

\section{DISCUSSION}

The present descriptive, retrospective study has evaluated DIDR in different subgroups of patients with T1D treated with second-generation basal insulin analogs for at least 6 months in real-life conditions and revealed no difference in DIDR between IGla-300 and IDeg neither globally nor in any of metabolic control subgroups analyzed. Despite the fact that both basal analogs were introduced in 2015, to date, few comparative studies have been published $^{32-36}$ and information about comparative DIDR come only from studies in patients with type 2 diabetes, which reported that patients treated with IGla-300 had higher DIDR compared with IDeg. ${ }^{35} 36$

Many studies have analyzed the DIDR in patients with T1D switching from basal insulins to IGla-300 or IDeg with non-concluding results. Thus, some recent RWS reported that patients with T1D using IGla-300, transferred from another basal insulin, have significant reductions in HbA1c levels, ${ }^{17223}$ with no change in weight ${ }^{172223}$ or DIDR. ${ }^{1723} 30$ However, other studies in routine practice settings have reported higher DIDR ranged from 6.5\% to $10.1 \%$ after switching to U300 from U100, mainly in the first 6 months. ${ }^{19} 2029$ On the other hand, in RCTs comparing IDeg with either glargine or detemir in patients with T1D, IDeg daily doses at end point are usually lower than comparators. ${ }^{132637}$ In RWS with patients with T1D, switching to IDeg from IGla-100 or detemir is associated with a $12 \%-13 \%$ reduction of both basal and prandial daily insulin doses, ${ }^{182128}$ mainly in patients who were previously on two injections of basal insulin. However, other studies in real-life conditions informed that IDeg doses in patients with T1D transferred from IGla-100 once-daily were equivalent. ${ }^{25-2731}$ 
Discrepancies in basal and total DIDR observed in studies with patients with T1D may potentially be, at least partly, explained by differences in the treated populations (HbA1c levels, age, race, weight and so on) and use of different insulin adjustment algorithms, mainly in RCTs where titration schedules for basal insulin are rather different from those used in routine clinical practice. Therefore, approximately half $(40 \%-60 \%)$ of total daily insulin doses in patients with T1D using multiple daily injections is given as basal insulin, dependent on body weight and insulin sensitivity, and the rest is divided into meal-related doses, mainly based on carbohydrate content. ${ }^{3839}$ In our population, daily basal insulin doses were $58 \%$ of the daily total doses, similarly to other national studies in T1D reporting that daily basal doses ranged $55 \%-63 \%$ of daily total insulin doses and could be explained, in part, for Mediterranean diet and lifestyle followed by the Spanish populations, ${ }^{2040}$ in contrast with studies in other countries in patients with T1D where daily basal insulin requirements usually are $\leq 50 \% .21273139$

RCTs have a high degree of internal validity but lower generalizability and its results cannot always be extrapolated to an unselected population. However, RWS provides a valuable additional source of evidence that complements clinical trial data by assessing the external validity of new therapies, thus bridging the knowledge gap between RCTs and clinical practice. ${ }^{41}$ The strengths of our study have been to reflect the current therapeutic approach in patients with T1D in real-life practice and have shown no difference in total, basal and prandial DIDR between patients with T1D using IGla-300 or IDeg.

There are some limitations to our study. First, observational retrospective studies can be limited by real-worldrelated biases with numerous confounders. However, retrospective observational studies may be closer to actual clinical practice that prospective observations that tend to alter the spontaneous behaviors of both clinicians and patients. Moreover, in our center the clinical and therapeutic data from patients with T1D are prospectively incorporated into a cumulative database, which is annually evaluated for quality control. This strategy allows us to detect and correct incomplete and erroneous clinical data and this makes the available information in the database to be robust. Second, the limited size of the sample enrolled in the present study warrants caution in the interpretation of results. Also, this retrospective survey was performed in a single specialist clinic for diabetes care, limiting the generalization of results. Finally, another potential limitation to the study is that hypoglycemic episodes and residual $\beta$-cell functions were not evaluated because those data were not incorporated into our database. Only time in hypoglycemia $<70 \mathrm{mg} / \mathrm{dL}$ in patients using freestyle libre has been analyzed and no difference was found between groups. However, the retrospective nature of the study would not have allowed reliable information on total and nocturnal hypoglycemia, whereas the expected incidence of severe hypoglycemia was probably too low to produce meaningful results on this sample size.

In conclusion, despite the fact that second-generation basal insulin analogs (IGla-300 and IDeg) were introduced in 2015 , to date, clinicians have insufficient information about differences or similarities in DIDR in patients with T1D using both long-acting basal insulin analogs. Our study provides relevant information in our patients with T1D with stable basal-bolus insulin injections, using IGla-300 or IDeg as the basal insulin, in whom we did not observe any difference in basal, prandial or total DIDR. However, prospective, randomized, multicenter study comparing both second-generation basal insulin analogs in patients with T1D is needed.

Contributors All authors have contributed equally to the planning, conduct and reporting of the work described in the article.

Funding The authors have not declared a specific grant for this research from any funding agency in the public, commercial or not-for-profit sectors.

\section{Competing interests None declared.}

\section{Patient consent for publication Not required.}

Ethics approval This study was approved by the Ethics Committee of province of Cádiz in February 2020 and all procedures followed were following the ethical standards of the Helsinki Declaration of 1964, as revised in 2013.

Provenance and peer review Not commissioned; externally peer reviewed.

Data availability statement All data relevant to the study are included in the article or uploaded as supplementary information.

Open access This is an open access article distributed in accordance with the Creative Commons Attribution Non Commercial (CC BY-NC 4.0) license, which permits others to distribute, remix, adapt, build upon this work noncommercially, and license their derivative works on different terms, provided the original work is properly cited, an indication of whether changes were made, and the use is non-commercial. See: http://creativecommons.org/ licenses/by-nc/4.0/.

\section{ORCID iD}

Florentino Carral San Laureano http://orcid.org/0000-0002-2607-971X

\section{REFERENCES}

1 Nathan DM, DCCT/EDIC Research Group. The diabetes control and complications trial/epidemiology of diabetes interventions and complications study at 30 years: overview. Diabetes Care 2014;37:9-16.

2 Diabetes Control and Complications Trial Research Group, Nathan DM, Genuth $\mathrm{S}$, et al. The effect of intensive treatment of diabetes on the development and progression of long-term complications in insulin-dependent diabetes mellitus. N Engl J Med 1993;329:977-86.

3 Nathan DM, Cleary PA, Backlund J-YC, et al. Intensive diabetes treatment and cardiovascular disease in patients with type 1 diabetes. N Engl J Med 2005;353:2643-53.

4 Herman WH, Braffett BH, Kuo S, et al. What are the clinical, quality-of-life, and cost consequences of 30 years of excellent vs. poor glycemic control in type 1 diabetes? J Diabetes Complications 2018;32:911-5.

5 Mathieu C, Gillard P, Benhalima K. Insulin analogues in type 1 diabetes mellitus: getting better all the time. Nat Rev Endocrinol 2017;13:385-99.

6 Cheng AYY, Patel DK, Reid TS, et al. Differentiating basal insulin preparations: understanding how they work explains why they are different. Adv Ther 2019:36:1018-30.

7 Walker GS, Chen JY, Hopkinson H, et al. Structured education using Dose Adjustment for Normal Eating (DAFNE) reduces long-term $\mathrm{HbA}_{1 \mathrm{c}}$ and $\mathrm{HbA}_{1 \mathrm{c}}$ variability. Diabet Med 2018;35:745-9.

8 Beck RW, Bergenstal RM, Laffel LM, et al. Advances in technology for management of type 1 diabetes. Lancet 2019;394:1265-73.

9 Kravarusic J, Aleppo G. Diabetes technology use in adults with type 1 and type 2 diabetes. Endocrinol Metab Clin North Am 2020;49:37-55.

10 Mair C, Wulaningsih W, Jeyam A, et al. Glycaemic control trends in people with type 1 diabetes in Scotland 2004-2016. Diabetologia 2019;62:1375-84.

11 Foster NC, Beck RW, Miller KM, et al. State of type 1 diabetes management and outcomes from the T1D exchange in 2016-2018. Diabetes Technol Ther 2019;21:66-72.

12 Home PD, Bergenstal RM, Bolli GB, et al. Glycaemic control and hypoglycaemia during 12 months of randomized treatment with insulin glargine $300 \mathrm{U} / \mathrm{mL}$ versus glargine $100 \mathrm{U} / \mathrm{mL}$ in people with type 1 diabetes (EDITION 4). Diabetes Obes Metab 2018;20:121-8.

13 Mathieu C, Hollander P, Miranda-Palma B, et al. Efficacy and safety of insulin degludec in a flexible dosing regimen vs insulin glargine in patients with type 
1 diabetes (begin: flex T1): a 26-week randomized, treat-to-target trial with a 26-week extension. J Clin Endocrinol Metab 2013;98:1154-62.

14 Lane W, Bailey TS, Gerety G, et al. Effect of insulin degludec vs insulin glargine $\mathrm{u} 100$ on hypoglycemia in patients with type 1 diabetes: the switch 1 randomized clinical trial. JAMA 2017:318:33-44.

15 Bergenstal RM, Bailey TS, Rodbard D, et al. Comparison of insulin glargine 300 Units $/ \mathrm{mL}$ and 100 Units $/ \mathrm{mL}$ in adults with type 1 diabetes: continuous glucose monitoring profiles and variability using morning or evening injections. Diabetes Care 2017:40:554-60.

16 Landstedt-Hallin L. Changes in $\mathrm{HbA1C}$, insulin dose and incidence of hypoglycemia in patients with type 1 diabetes after switching to insulin degludec in an outpatient setting: an observational study. Curr Med Res Opin 2015;31:1487-93.

17 Abitbol A, Brown RE, Jiandani D, et al. Real-world health outcomes of insulin glargine $300 \mathrm{U} / \mathrm{mL}$ vs insulin glargine $100 \mathrm{U} / \mathrm{mL}$ in adults with type 1 and type 2 diabetes in the Canadian LMC diabetes patient registry: the reality study. Can J Diabetes 2019:43:504-9.

18 Ponzani P, Berra C, Di Lelio A, et al. Switching patients with type 1 diabetes to insulin degludec from other basal insulins: real-world data of effectiveness and safety. Diabetes Ther 2020;11:97-105.

19 Oriot $P$, Jérémie $W$, Buysschaert $M$. Outcomes of glycemic control in type 1 diabetic patients switched from basal insulin glargine $100 \mathrm{U} / \mathrm{ml}$ to glargine $300 \mathrm{U} / \mathrm{ml}$ in real life. Expert Rev Endocrinol Metab 2018;13:167-71.

20 Pujante Alarcón P, Rodríguez Escobedo R, García Urruzola F, et al. Experience after switching from insulin glargine 4100 to glargine U300 in patients with type 1 diabetes mellitus. A study after one year of treatment in real life. Endocrinol Diabetes Nutr 2019;66:210-6.

21 Siegmund T, Tentolouris N, Knudsen ST, et al. A European, multicentre, retrospective, non-interventional study (EU-TREAT) of the effectiveness of insulin degludec after switching basal insulin in a population with type 1 or type 2 diabetes. Diabetes Obes Metab 2018;20:689-97.

22 Svensson A-M, Ekelund J, Miftaraj M, et al. Efficacy and safety of treatment with new basal insulin analogues in type 1 diabetes: nation-wide survey. Diabetes Ther 2020;11:725-34.

23 Pang T, Bain SC, Black RNA, et al. A multicentre, UK, retrospective, observational study to assess the effectiveness of insulin glargine 300 units/ $\mathrm{ml}$ in treating people with type 1 diabetes mellitus in routine clinical practice (SPARTA). Diabet Med 2019;36:110-9.

24 Bohn B, Bramlage P, Wagner $C$, et al. [Which patients from routine care use the new insulin analogue glargine U300 compared to patients with glargine U100: A multicenter analysis of 14,123 patients with insulin glargine from die diabetes registries DPV and DIVE]. Wien Med Wochenschr 2018;168:415-22.

25 Bohn B, Zimmermann A, Wagner C, et al. Real-life experience of patients starting insulin degludec. A multicenter analysis of 1064 subjects from the German/Austrian DPV registry. Diabetes Res Clin Pract 2017;129:52-8.

26 Birkeland KI, Home PD, Wendisch U, et al. Insulin degludec in type 1 diabetes: a randomized controlled trial of a new-generation ultra-long-acting insulin compared with insulin glargine. Diabetes Care 2011;34:661-5.
27 Lualdi C, Silverii A, Dicembrini I, et al. Adjustment of insulin doses when switching from glargine $100 \mathrm{U} / \mathrm{ml}$ or detemir to degludec: an observational study. J Endocrinol Invest 2019;42:319-26.

28 Komuro M, Inoue G, Tabata M, et al. Insulin degludec requires lower bolus insulin doses than does insulin Glargine in Japanese diabetic patients with insulin-dependent state. J Diabetes Sci Technol 2015;9:632-8.

29 van Mark G, Lanzinger S, Sziegoleit S, et al. Characteristics of patients with type-1 or type-2 diabetes receiving insulin glargine U300: an analysis of 7268 patients based on the DPV and dive registries. Adv Ther 2019;36:1628-41.

30 Gradišer M, Berković MC, Bilić-Ćurčić I. Changes in HbA1C and hypoglycemic episodes in type 1 diabetes patients after switching to insulin glargine U300: pilot study. Diabetes Res Clin Pract 2017;129:144-7.

31 Suzuki J, Yamakawa T, Nagakura J, et al. Efficacy of switching from insulin glargine to insulin degludec in patients with type 1 diabetes: a 16-week retrospective study. Diabetol Int 2017;8:45-51.

32 Heise T, Nørskov M, Nosek L, et al. Insulin degludec: Lower day-to-day and within-day variability in pharmacodynamic response compared with insulin glargine $300 \mathrm{U} / \mathrm{mL}$ in type 1 diabetes. Diabetes Obes Metab 2017;19:1032-9.

33 Bailey TS, Pettus J, Roussel R, et al. Morning administration of $0.4 \mathrm{U}$ / $\mathrm{kg} /$ day insulin glargine $300 \mathrm{U} / \mathrm{mL}$ provides less fluctuating 24 -hour pharmacodynamics and more even pharmacokinetic profiles compared with insulin degludec 100U/mL in type 1 diabetes. Diabetes Metab 2018:44:15-21.

34 Miura H, Sakaguchi K, Otowa-Suematsu N, et al. Effects of insulin degludec and insulin glargine U300 on glycaemic stability in individuals with type 1 diabetes: a multicentre, randomized controlled crossover study. Diabetes Obes Metab 2020;22:2356-63.

35 Tibaldi J, Hadley-Brown M, Liebl A, et al. A comparative effectiveness study of degludec and insulin glargine $300 \mathrm{U} / \mathrm{mL}$ in insulin-naive patients with type 2 diabetes. Diabetes Obes Metab 2019;21:1001-9.

36 Rosenstock J, Cheng A, Ritzel R, et al. More similarities than differences testing insulin glargine $300 \mathrm{Units} / \mathrm{mL}$ versus insulin degludec $100 \mathrm{Units} / \mathrm{mL}$ in InsulinNaive type 2 diabetes: the randomized head-to-head bright trial. Diabetes Care 2018;41:2147-54.

37 Vora J, Christensen T, Rana A, et al. Insulin degludec versus insulin glargine in type 1 and type 2 diabetes mellitus: a meta-analysis of endpoints in phase $3 \mathrm{~A}$ trials. Diabetes Ther 2014;5:435-46.

38 Janež A, Guja C, Mitrakou A, et al. Insulin therapy in adults with type 1 diabetes mellitus: a narrative review. Diabetes Ther 2020;11:387-409.

39 Castellano E, Attanasio R, Giagulli VA, et al. The basal to total insulin ratio in outpatients with diabetes on basal-bolus regimen. J Diabetes Metab Disord 2018;17:393-9.

40 Gómez FJ, Silva J, Garcia A. Experiencia en ISCl en el área de salud La Mancha Centro. Endocrinol Diabetes Nutr 2019;66:100.

41 Rothwell PM. External validity of randomised controlled trials: "to whom do the results of this trial apply?". Lancet 2005;365:82-93. 